\title{
Formulation, characterization and in-vitro evaluation of solid lipid nanoparticles for the delivery of a new anticancer agent, $1 \mathrm{H}$-pyrazolo[3,4-d] pyrimidine derivative
}

\author{
Amani Elsayed ${ }^{1 *}$, Amany Belal ${ }^{2}$ \\ ${ }^{1}$ Pharmaceutics \& Industrial Pharmacy Department, College of Pharmacy, ${ }^{2}$ Pharmaceutical Chemistry Department, College of \\ Pharmacy, Taif University, Taif 21974, Kingdom of Saudi Arabia
}

*For correspondence: Email: e.amani@tu.edu.sa; Tel: +966-567716613

Sent for review: 12 March 2021

Revised accepted: 29 April 2021

\begin{abstract}
Purpose: To investigate the physicochemical properties and in vitro cytotoxic effect of a potent epidermal growth factor receptor-tyrosine kinase (EGFRWT-TK) inhibitor, 1H-pyrazolo [3,4-d] pyrimidine (FEP) derivative and formulated as solid lipid nanoparticles (SLNS) using stearic acid (ST) or glycerylmonostearate (GMS).

Methods: The SLNs were prepared by hot homogenization and sonication method. The effect of formulation variables on particle size, zeta potential and polydispersity index (PDI) of SLNs were studied, and an optimized formulation selected. Drug-excipient interactions were assessed by differential scanning calorimetry (DSC) and Fourier Transform Infrared (FTIR). Mammary gland breast cancer (MCF-7) and human colon cancer (HCT116) human cell lines were used to evaluate the cytotoxic activity of the free and FEP-loaded SLNs.

Results: The particle size of the SLNs was in the range of $138-819 \mathrm{~nm}$, while zeta potential varied from -15 to $-20 \mathrm{~nm}$. FEP-loaded SLNs exhibited significant cytotoxic effect compared to the free drug and doxorubicin in the two cell lines $(p<0.05)$. The activity was higher in HCT116 compared with MCF7 cells $(p<0.007)$. The concentration of FEP loaded SLNs, free drug and doxorubicin that showed 50 $\%$ inhibition (IC50) for breast cancer cells were $1.06 \pm 0.09,2.58 \pm 0.16$ and $3.75 \pm 0.4 \mu \mathrm{g} / \mathrm{ml}$, respectively.

Conclusion: The findings show that FEP-loaded SLNs have greater in-vitro cytotoxic activity than the free FEP, and thus, might improve cancer therapy in humans.
\end{abstract}

Keywords: Anticancer, Solid lipid nanoparticles, 1H-pyrazolo[3,4-d] pyrimidine, EGFRWT-TK, Poloxamer 188, Glyceryl monostearate

\begin{abstract}
This is an Open Access article that uses a fund-ing model which does not charge readers or their institutions for access and distributed under the terms of the Creative Commons Attribution License (http://creativecommons.org/licenses/by/4.0) and the Budapest Open Access Initiative (http://www.budapestopenaccessinitiative.org/read), which permit unrestricted use, distribution, and reproduction in any medium, provided the original work is properly credited.

Tropical Journal of Pharmaceutical Research is indexed by Science Citation Index (SciSearch), Scopus, International Pharmaceutical Abstract, Chemical Abstracts, Embase, Index Copernicus, EBSCO, African Index Medicus, JournalSeek, Journal Citation Reports/Science Edition, Directory of Open Access Journals (DOAJ), African Journal Online, Bioline International, Open-J-Gate and Pharmacy Abstracts
\end{abstract}

\section{INTRODUCTION}

A new $1 \mathrm{H}$-pyrazolo [3,4-d] pyrimidine derivative has been synthesized, and it showed significant anticancer potential [1]. Its mechanism of action involves the inhibition of epidermal growth factor receptor-tyrosine kinase (EGFR-TK), which have been shown to be over-expressed in many types of tumors, such as breast and hepatic cancers [1]. However, this compound has poor water 
solubility that may affect its bioavailability and efficacy [2]. Nanotechnology approach was explored to improve anticancer activity of FEP. Solid lipid nanoparticles (SLNs) was thought to be the suitable option, as they incorporate lipophilic drugs efficiently. It has been reported that lipid based-nanosystems improve cytotoxicity of many chemotherapeutic drugs, including doxorubicin, paclitaxel, sorfenib and dihydroartemisinin [3,4]. SLNs are passively targeting tumor cells due to their enhanced permeability and retention nature [4]. The surface of SLNs could also be modified for active targeting of tumor cells [5]. In addition, SLNs have the ability to reverse the resistance of chemotherapeutic agents in multi-drug resistant cancer cells [6]. SLNs have proven their efficacy in various tumor types e.g., breast, hepatic, bladder, lung, brain and leukemia [3,7].

Although FEP showed promising in-vitro cytotoxic effect in EGFR-containing cells, its invivo performance might face a variety of obstacles, such as rapid clearance, poor bioavailability and toxicity of vital organs. All these points were taken into consideration in order to enhance the efficacy of this substance. Consequently, SLNs were developed and investigated as a carrier of the chemotherapeutic compound. Two lipid matrices (stearic acid and its ester glycerylmonostearte) and two stabilizers (Tween 80 and poloxamer 188) were chosen to fabricate SLNs. Eight preparations were formulated, and their physicochemical properties were determined. The most promising preparation was chosen for further characterization. Its in-vitro cytotoxic activity was studied using MTT assay method and compared to free drug and doxorubicin.

\section{EXPERIMENTAL}

\section{Chemicals and cell lines}

Stearic acid, poloxamer 188 and glyceryl monostearate were purchased from Merck, Darmstadt, Germany. The reagents - RPMI-1640 medium, MTT and DMSO were purchased from Sigma Chemical Co. (St. Louis, USA), fetal bovine serum was purchased from GIBCO (UK). Two human tumor cell lines namely: mammary gland breast cancer (MCF-7) and colon cancer (HCT116) were obtained from ATCC via Holding company for biological products and vaccines (VACSERA), Cairo, Egypt.

\section{Synthesis of anticancer agent}

It was synthesized by the method described in a Gaber et al [1] publication. Its structure was depicted in Figure 1.

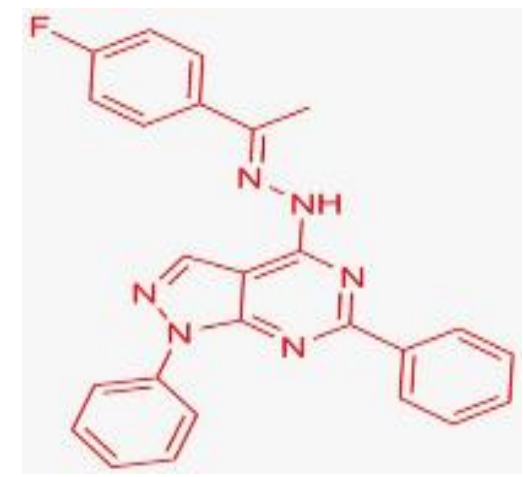

Figure 1: Chemical structure of 4-(2-(1-(4Fluorophenyl)ethylidene)hydrazinyl)-1,6-diphenyl-1Hpyrazolo[3,4-d] pyrimidine

\section{Preparation of SLNs}

For formulation of SLNs, two lipids matrices and two surfactants were investigated (glyceryl monostearate and stearic acid as lipids; tween 80 and poloxamer 188 as surfactants). SLNs were prepared using hot homogenization and sonication method. Briefly in a beaker, the designated amount of lipid was melted by heating to $70{ }^{\circ} \mathrm{C}$. $10 \mathrm{mg}$ of chemotherapeutic substance were dispersed in the melted lipid. Other beaker containing $100 \mathrm{ml}$ of distilled water was heated to the same temperature and used to dissolve the surfactant. The aqueous phase was added slowly to the lipid phase on a hot platemagnetic stirrer under vigorous stirring of 850 rpm. The mixture was homogenized for $5 \mathrm{~min}$, and then probe-sonicated for another $5 \mathrm{~min}$. The Type and ratio of lipids and surfactants used in production of SLNs were depicted in Table 1.

\section{Determination of particle size and zeta potential}

The physical characteristics of solid lipid nanoparticles (particle size distribution, PDI and zeta potential) were determined using Zetasizer Nano-ZS (Malvern Instruments, UK) at $25^{\circ} \mathrm{C}$. The average of three experiments and standard deviations were reported.

\section{Transmission electron microscopy (TEM)}

Morphological analysis of the optimum preparation was performed with HR transmission electron microscopy (JEOL JEM-2100). One drop of diluted sample was put on a copper grid and allowed to dry. The dried sample was then stained with $1 \%$ phosphotungstic acid and observed by transmission electron microscopy [8]. 


\section{Differential scanning calorimetry (DSC)}

DSC experiments were performed using DSC (Shimadzu DSC-60, Kyoto, Japan). $4 \mathrm{mg}$ from each sample was crimpled in standard aluminum pan, while another empty pan was used as a reference and scanned from 0 to $300{ }^{\circ} \mathrm{C}$ at scanning rate of $5^{\circ} \mathrm{C} / \mathrm{min}$.

\section{Fourier transform infrared spectroscopy (FTIR)}

FTIR was carried out using FTIR (Thermo Scientific, Nicolet iS50). Samples were made into pellets using $\mathrm{KBr}$ and subjected to analysis under transmittance mode from 500 to $4000 \mathrm{~cm}-1$.

\section{In-vitro cytotoxicity studies}

The cell lines mentioned above were used to evaluate the effect of free drug, drug loaded SLNs and doxorubicin on cell growth using the MTT assay. The cells were seeded in RPMI1640 medium with $10 \%$ fetal bovine serum at 37 ${ }^{\circ} \mathrm{C}$ in a $5 \% \mathrm{CO}_{2}$ incubator. Then penicillin (100 units $/ \mathrm{ml})$ and streptomycin $(100 \mu \mathrm{g} / \mathrm{ml})$ were added. The cells were cultured in a 96-well plate separately at a density of $1.0 \times 10^{4}$ cells/well at $37^{\circ} \mathrm{C}$ for $48 \mathrm{~h}$ under $5 \% \mathrm{CO}_{2}$, followed by the addition of various concentrations of compounds $(6.25-100 \mu \mathrm{g} / \mathrm{ml})$ and further incubation for $4 \mathrm{~h}$. Then $20 \mu \mathrm{l}$ of MTT solution at $5 \mathrm{mg} / \mathrm{ml}$ was added and left for further $4 \mathrm{~h}$. Next, $100 \mu \mathrm{l}$ dimethyl sulfoxide (DMSO) was transferred to each well to dissolve the purple formazan colour results from conversion of yellow tetrazolium bromide (MTT) by mitochondrial succinate dehydrogenase in viable cells. A plate reader (EXL 800, USA) was used to measure absorbances at $570 \mathrm{~nm}$. The percentage of relative cell viability was determined using the following equation:

$\%$ relative cell viability $=($ Absorbance of treated samples/Absorbance of untreated sample) $\times 100$.
The mean drug concentration needed to inhibit the growth of $50 \%$ of cells (IC50\%) was also calculated. Experiments were conducted in triple, and the mean and standard deviations were calculated [9].

\section{Statistical analysis}

Statistical tests were performed with Excel 2013 software (Microsoft Corporation, USA). One-way analysis was used to calculate inter-group variations. Statistically significant differences were considered, and assumed at $p<0.05$.

\section{RESULTS}

\section{Physicochemical characteristics of SLNs}

Different formulation variables were studied to optimize SLNs as depicted in Table 1. First, 100 $\mathrm{mg}$ of either GMS or ST (stearic acid) were stabilized by $300 \mathrm{mg}$ of poloxamer 188 or Tween 80. Combination of GMS and poloxamer 188 resulted in smaller particle size $(138-249 \mathrm{~nm})$ compared to other preparations (495 - $819 \mathrm{~nm})$. Consequently, further studies were carried out using GMS as lipid matrix and Poloxamer 188 as stabilizer. To investigate the influence of GMS and poloxamer 188 on quality attributes of SLNs, their amounts were changed from 100 to $300 \mathrm{mg}$, and their physicochemical properties were recorded in Table 1. F4 (200 mg of GMS and 300 $\mathrm{mg}$ of Poloxamer 188) had the smallest particle size and PDI values of $138.5 \pm 1.98 \mathrm{~nm}$ and 0.37 \pm 0.03 respectively, and reasonable zeta potential value $-20.14 \pm 2.18 \mathrm{mv}$ (Figure $2 \mathrm{a}$ and b) was considered as the optimum SLNs preparation. Subsequent characterization and invitro cytotoxicity studies were performed with SLNs prepared using the above-mentioned amounts. Zeta potential values varied from -15 to $-25 \mathrm{mv}$ when the formulation variables were changed.

Table 1: Composition and physicochemical characteristics of various formulations

\begin{tabular}{llcccccc}
\hline Batch & \multicolumn{3}{c}{ Composition } & \multicolumn{3}{c}{ Physical characteristics } \\
\cline { 2 - 7 } & $\begin{array}{l}\text { GMS } \\
(\mathbf{m g})\end{array}$ & $\begin{array}{c}\text { ST acid } \\
(\mathbf{m g})\end{array}$ & $\begin{array}{c}\text { Tween } \\
\mathbf{8 0}(\mathbf{m g})\end{array}$ & $\begin{array}{c}\text { Poloxame } \\
\mathbf{r} \mathbf{1 8 8}(\mathbf{m g})\end{array}$ & $\begin{array}{c}\text { Particle size } \mathbf{I} \\
\text { SD }\end{array}$ & PDI \pm SD & $\begin{array}{c}\text { Zeta Potential } \pm \\
\text { SD }\end{array}$ \\
\hline F1 & 100 & & & 100 & $249.9 \pm 6.32$ & $0.35 \pm 0.045$ & $-18.6 \pm 0.72$ \\
& & & & & & & \\
F2 & 100 & & & 200 & $222.73 \pm 1.03$ & $0.48 \pm 0.09$ & $-18.07 \pm 1.12$ \\
F3 & 100 & & & 300 & $245.00 \pm 4.63$ & $0.39 \pm 0.06$ & $-20.73 \pm 0.35$ \\
F4 & 200 & & & 300 & $138.50 \pm 1.98$ & $0.37 \pm 0.03$ & $-20.14 \pm 2.18$ \\
F5 & 300 & & & 300 & $193.37 \pm 5.76$ & $0.42 \pm 0.03$ & $-20.60 \pm 1.51$ \\
F6 & 100 & & 300 & & $495.36 \pm 10.50$ & $0.50 \pm 0.06$ & $-15.57 \pm 4.30$ \\
F7 & & 100 & 300 & & $819.75 \pm 11.30$ & $0.58 \pm 0.05$ & $-25.40 \pm 1.31$ \\
F8 & & 100 & & 300 & $589.20 \pm 9.84$ & $0.54 \pm 0.01$ & $-16.57 \pm 0.70$ \\
\hline
\end{tabular}




\section{Thermal and morphological features}

Figure $2 \mathrm{c}$ shows TEM picture of SLNs. The particles were almost existing as discrete units and were not aggregated. SLNs were roughly spherical with irregular surface. There was a difference in contrast between the core lipid matrix and surface corona of poloxamer 188. Kumar et al also noticed the core-corona contrast variation [10].
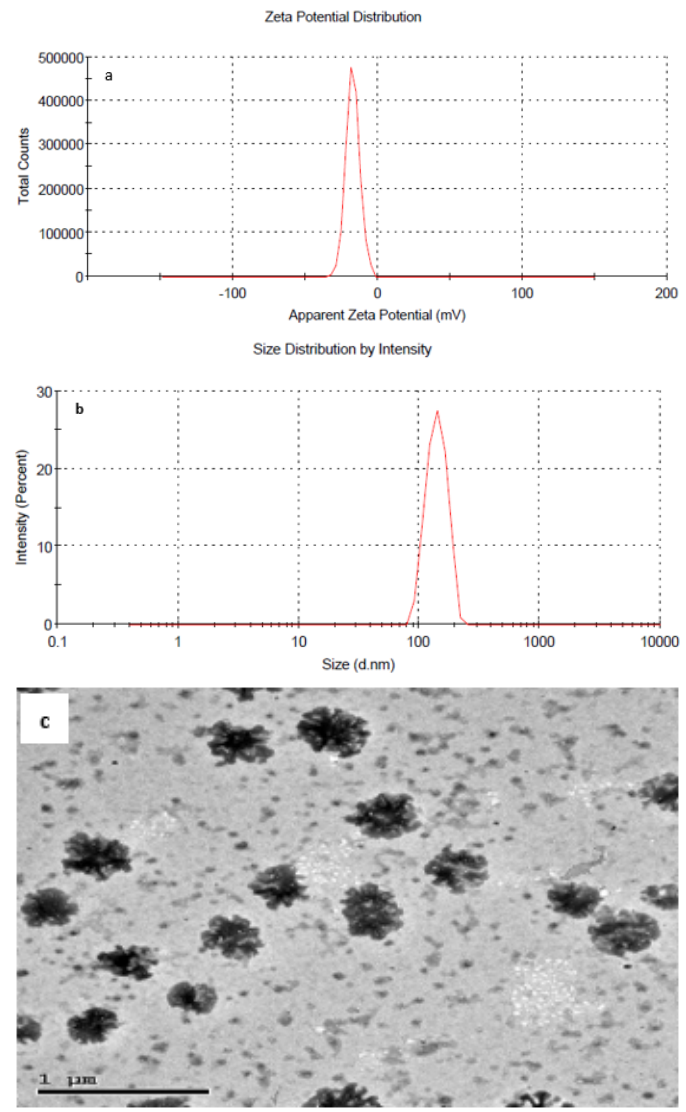

Figure 2: Zeta potential (a) size distribution (b), TEM Micrograph (c) of FEP-SLNs fabricated using $200 \mathrm{mg}$ GMS, $300 \mathrm{mg}$ poloxamer 188 and $10 \mathrm{mg}$ FEP. Nanoparticles were stained with $1 \%$ phosphotungstic acid

\section{Thermal characteristics}

DSC for individual components, physical mixture and the optimum formula was run from 20 to 300 ${ }^{\circ} \mathrm{C}$ as depicted in Figure 3. GMS showed endothermic peak at $62.21^{\circ} \mathrm{C}$, which was less than the reported value $71^{\circ} \mathrm{C}$ [11]. This might be due to partial esterification of the GMS used in this study, as evidenced by negative zeta potential of nanoparticles manufactured from it. Poloxamer 188 displayed melting peak at 56.3 ${ }^{\circ} \mathrm{C}$, which was comparable to previous work. [12]. The endothermic peak of the pure drug appeared at $250.3^{\circ} \mathrm{C}$, and this result was in agreement with the previously published work [1]. Physical mixture exhibits a melting peak at $51.4{ }^{\circ} \mathrm{C}$. On the contrary, SLNs showed SLNs thermogram with a single peak at $52.1^{\circ} \mathrm{C}$.

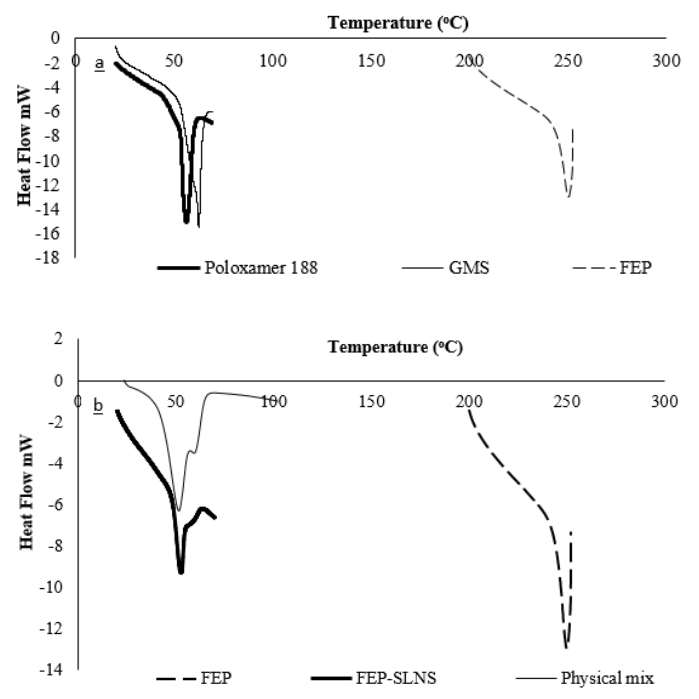

Figure 3: DSC thermogram of (a) GMS, Poloxamer 188, FEP and (b) physical mixture, FEP-SLNs, FEB

\section{Infrared spectra}

FTIR of SLNs components and FEP-SLNs were displayed in Figure 4. GMS spectrum characteristic peaks were $(\mathrm{C}=\mathrm{O})$ stretching, which appeared at $1735.6 \mathrm{~cm}^{-1}$ and $(\mathrm{C}-\mathrm{H})$ stretching at $2850.2 \mathrm{~cm}^{-1}$ and $2917.8 \mathrm{~cm}^{-1}$. [13]. Poloxamer 188 showed characteristic peaks between 3000-1000 $\mathrm{cm}^{-1}$. Peaks $1111.7 \mathrm{~cm}^{-1}$ assigned to (C-O) stretch and $1345.1 \mathrm{~cm}^{-1}$ (in plane O-H) [14]. FTIR of the FEP showed peaks at $3211.6 \mathrm{~cm}^{-1}, 3090 \mathrm{~cm}-1$ and $2970 \mathrm{~cm}^{-1}$, which were assigned to $(\mathrm{N}-\mathrm{H})$ stretch, aromatic $(\mathrm{C}-\mathrm{H})$ stretch, and aliphatic $(\mathrm{CH})$ stretch, respectively [1]. On the other hand, the spectrum of SLNs and physical mixture showed $(\mathrm{C}=\mathrm{O})$ stretching of GMS at $1730 \mathrm{~cm}^{-1}$ and peak of poloxamer 188 at about $1111 \mathrm{~cm}^{-1}$. Drug peaks did not appear in the physical mixture or SLNs, and this might be due to the effect of dilution, since the drug amount was very small at about $2 \%$ of the total preparation.

\section{Cytotoxicity}

Figure 5 indicated that FEP- SLNs, free drug and doxorubicin decreased cell viability in a dose dependent manner in the two studied cell lines. Drugs encapsulated in SLNs showed significantly lower $\mathrm{IC}_{50}$ value $(\mathrm{P}<0.05)$ (Table 2$)$ and remarkable difference in cytotoxic effect in MCF$7\left(P=4.1^{*} 10-5\right)$, compared to the free FEP and 
DOX (Table 2). In contrast, empty SLNs percentage viabilities were above $90 \%$, indicating that the cytotoxicity was not due to components of SLNs.

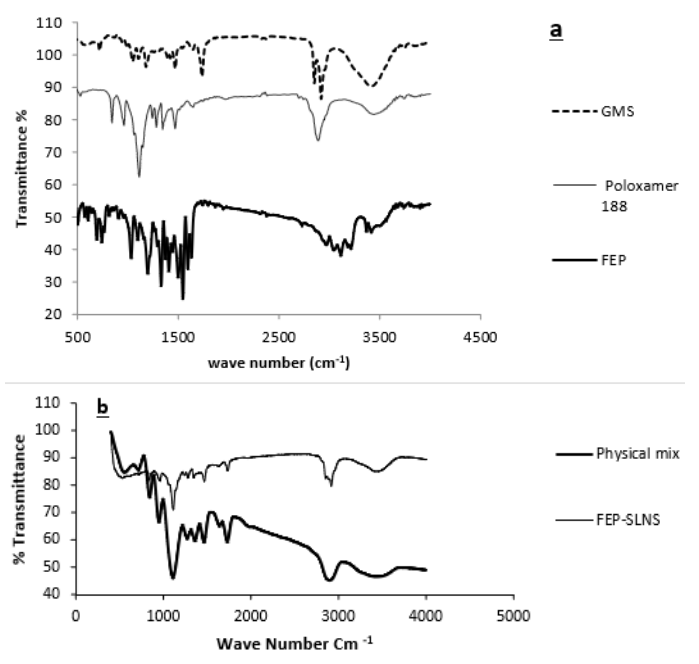

Figure 4: FTIR spectra of (a) GMS, Poloxamer 188 and FEP; (b) physical mixture and FEPSLNs
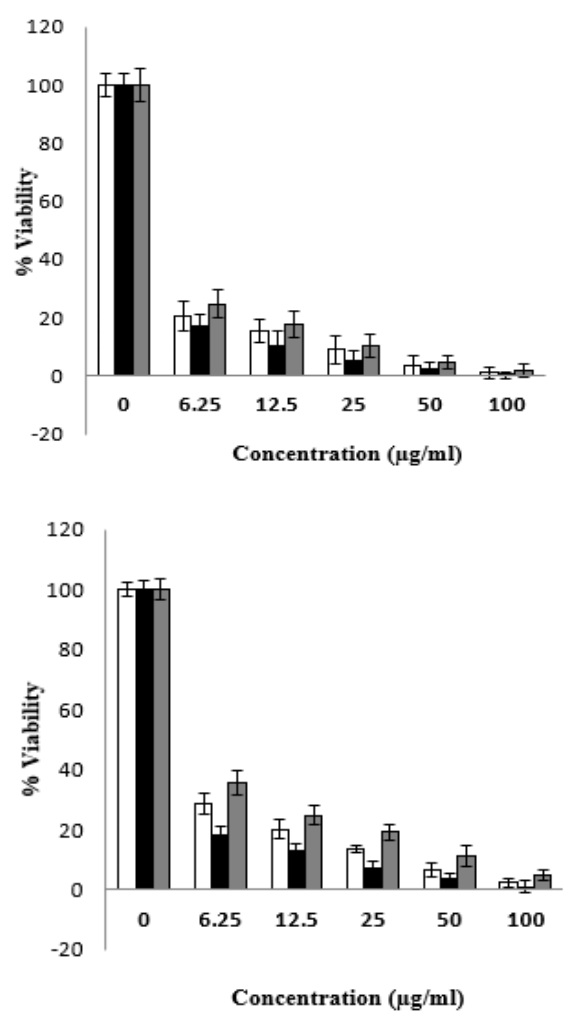

Figure 5: In-vitro cytotoxic effect of different formulations in (a) HCT116 and (b) MCF-7 cancer cells after $24 \mathrm{~h}$ incubation. Free drug $(\square)$, FEP-SLNs $(\square)$, DOX $(\square)$. Percentage viability was evaluated by MTT assay. Data are expressed as mean \pm SD $(n=3)$
Table 2: Cytotoxicity (IC 50 of SLNs formulations)

\begin{tabular}{lccc}
\hline \multirow{2}{*}{ Formulation } & \multicolumn{2}{c}{ Cytotoxicity $\left(\right.$ IC $\left._{50 \%}\right)$} & \\
\cline { 2 - 3 } & HCT116 & MCF-7 & $\begin{array}{c}\text { P- } \\
\text { value }\end{array}$ \\
\hline Doxorubicin & $1.87 \pm 0.6$ & $3.75 \pm 0.4$ & 0.019 \\
FEP- & $0.82 \pm 0.07$ & $1.06 \pm 0.09$ & 0.007 \\
encapsulated in & & & \\
SLNs & & & \\
FEP & $1.59 \pm 0.12$ & $2.58 \pm$ & 0.008 \\
$P$-value & 0.025 & 0.16 & \\
\hline
\end{tabular}

\section{DISCUSSION}

Inhibitors of wild-type epidermal growth factor receptor-tyrosine kinase (EGFRWT-TK) showed promising results in cancer therapy [15]. Anticancer efficacy of FEP was approved by Gaber et al [1]. However, its anticancer potential could be hindered by its poor water solubility. To improve its effectiveness, SLNs were developed, since they offer several advantages for delivery of poorly water-soluble drugs.

SLNs manufactured using poloxamer 188 as surfactant exhibited remarkably lower particle sizes (138-245 $\mathrm{nm}$ ) and polydispersity, compared to those prepared with Tween $80(495-819 \mathrm{~nm})$. This could be attributed to the good emulsification power of poloxamer 188 , due to its higher HLB [>24] value compared to that of Tween 80 which is 15 . This result was in good correlation with previous study [16]. No specific trend in particle size was observed when poloxamer 188: GMS ratio was increased from $1: 1$ to $3: 1$, neither when GMS: poloxamer 188 ratio was varied from $1: 1$ to $3: 1$. Minimum particle size was obtained when the ratio of GMS to poloxamer 188 was 2:3 as shown on Table 1 . When stearic acid was used as lipid matrix, particles presented a higher size compared to GMS-containing formulations. The quality of the produced SLNs depends largely on the properties of the pre-emulsion, crystallization behaviour of the two matrices when exposed to heating, cooling processes during production, polarity, melting point and viscosity of the lipids [17].

All SLNs preparations displayed negative charge resulting from the ionization of carboxyl group of stearic acid for stearic acid-SLNs, or ionization of fatty acids released from the hydrolysis of GMS [18]. SLNs containing ST and Tween 80 displayed the highest zeta potential values, whereas those fabricated using GMS and Tween 80 showed the lowest values. This is to be expected since stearic acid is a fatty acid and it is more easily dissociated compared to the GMS, which is ester. Zeta potential of SLNs composed 
of GMS and poloxamer 188 did not change significantly when the component amounts were altered. The presence of charge and steric stabilization by poloxamer 188 contributed to the stability of SLNs. Additionally, the negatively charged nanosystems might cause less damage to cells compared with cationic ones [5].

In Figure 3, the endothermic peaks of both the physical mixture and SLNs were almost similar and somewhat broad. This could be ascribed to the GMS and poloxamer 188 mixture. Lowering of the melting point of GMS when incorporated into SLNs was attributed to the change in crystallinity during preparation and/or the presence of poloxamer 188. Other researchers reported a shift of GMS endothermic peak to a lower temperature when it was used as a lipid matrix [13]. The endothermic peak that corresponds to the drug melting point was not noted in the thermograms of physical mixture and SLNs. This result proposes a molecular dispersion of the chemotherapeutic agent in the lipid matrix, which agrees well with other researchers' findings [19]. The enthalpy of fusion of SLNs $(\Delta \mathrm{H}) 53.48 \mathrm{~J} / \mathrm{g}$ was much lower than that of the physical mixture $(129.94 \mathrm{~J} / \mathrm{g}$ ) and bulk lipid $(148.46 \mathrm{~J} / \mathrm{g})$, indicating a reduction of the crystallinity of the lipid [20].

In-vitro cytotoxicity was evaluated in two celllines, HCT116 and MCF-7. These cell-lines were chosen because FEP has anti EGFR-TK, which is a therapeutic target for many solid tumors, such as breast and colorectal cancers [1]. The activity was higher in colon cancer (HCT116) compared to mammary gland breast cancer (MCF-7), as indicated by the tabulated $p$-values (Table 2). This result was interesting since colorectal cancers are the most aggressive type of cancers, and represents $10 \%$ of cancer cases worldwide. Two approved monoclonal antibodies, cetuximab (Erbitux $®)$ and panitumumab (Vectibix®), showed activity against colorectal cancer, and their activity was related to the inhibition of the overexpressed wild-type EGFR [21].

The enhanced effect might be due to the ability of SLNs to accumulate in the tumor passively [4]. In addition, the presence of poloxamer 188 also had a positive effect. In a study conducted by Allotey-Babington et al [22], it was found that ploxamer 188 enhances the uptake of nanoparticles into cell lines to a greater extent compared to other types of poloxamers, such as Pluronic F-108, pluronic F-127. Another study demonstrated that Docetaxel-loaded nanoparticles coated with poloxamer 188 were more effective in breast cancers than uncoated candidates [23]. All these factors accounted for the enhanced cytotoxic activity of FEP-loaded SLNs.

\section{CONCLUSION}

Nano-sized GMS-poloxamer 188 has been successfully developed and characterized as a suitable carrier for the chemotherapeutic substance, FEP. The derived formulations enhance cytotoxic efficacy, as evidenced by low cell viability in the two cell lines, and the lowest $\mathrm{IC}_{50}$ among the tested compounds. Thus, the formulations can be further developed for the management of cancer.

\section{DECLARATIONS}

\section{Acknowledgement}

This work was supported by Taif University, Taif, Kingdom of Saudi Arabia under grant no. $1 / 438 / 5870$. The authors would like to thank Ahmed Gaber for the synthesis of cytotoxic drug, and Ahmed Belal for the technical support in invitro cytotoxicity studies.

\section{Conflict of interest}

No conflict of interest is associated with this work.

\section{Contribution of authors}

We declare that this work was done by the authors named in this article and all liabilities pertaining to claims relating to the content of this article will be borne by the authors.

\section{Open Access}

This is an Open Access article that uses a funding model which does not charge readers or their institutions for access and distributed under the terms of the Creative Commons Attribution License (http://creativecommons.org/licenses/by/ 4.0) and the Budapest Open Access Initiative (http://www.budapestopenaccessinitiative.org/rea d), which permit unrestricted use, distribution, and reproduction in any medium, provided the original work is properly credited.

\section{REFERENCES}

1. Gaber $A A$, Bayoumi AH, El-morsy AM, Sherbiny FF, Mehany $A$, Ibrahim $H$, Eissa IH. Design, synthesis and anticancer evaluation of 1H-pyrazolo[3,4-d] pyrimidine derivatives as potent EGFRWT and EGFRT790M 
inhibitors and apoptosis inducers. Bioorg Chem 2018, 80: 375-395.

2. Sanna M, Sicilia G, Alazzo A, Singh N, Musumeci $F$, Schenone S, Spriggs K, Burley J, Garnett M, Taresco V, Alexander C. Water solubility enhancement of pyrazolo[3,4-d] pyrimidine derivatives via miniaturized polymer-drug microarrays. ACS Med Chem Lett 2018, 9(3): 193-197.

3. Zheng G, Zheng M, Yang B, Fu H, Li Y. Improving breast cancer therapy using doxorubicin loaded solid lipid nanoparticles: Synthesis of a novel arginine-glycineaspartic tripeptide conjugated, $\mathrm{pH}$ sensitive lipid and evaluation of the nanomedicine in vitro and in vivo. Biomed Pharmacother 2019, 116: 109006.

4. Wong HL, Bendayan R, Rauth AM, Li Y, Wu XY. Chemotherapy with anticancer drugs encapsulated in solid lipid nanoparticles. Adv Drug Deliv Rev 2007, 59: 491-504.

5. Sankar V, Penmetsa SD, Sabarinath C. Folate conjugated solid lipid nanoparticles of carboplatin for targeting cancer cells. Drug Deliv Lett 2012, 2: 162-170.

6. Lee S-E, Lee Ch, Ahn J, Kim D-H, Lee J, Lee J-Y, Choi J-S, Park J-S. Hyaluronic acid-coated solid lipid nanoparticles to overcome drug-resistance in tumor cells. J Drug Deliv Sci Technol 2019, 50: 365-371.

7. Bayón-Cordero L, Alkorta I, Arana L. Application of solid lipid nanoparticles to improve the efficiency of anticancer drugs. Nanomaterials 2019, 9: 474-494.

8. Moolakkadath T, Aqil M, Ahad A, Imam S. Development of transethosomes formulation for dermal fisetin delivery: Box-Behnken design, optimization, in vitro skin penetration, vesicles-skin interaction and dermatokinetic studies. Artif Cells Nanomed Biotechnol 2018, 46 (sup2): 755-765.

9. Denizot F, Lang R. Rapid colorimetric assay for cell growth and survival Modifications to the tetrazolium dye procedure giving improved sensitivity and reliability. J Immunol Methods 1986, 22: 89, 271-277.

10. Kumar $R$, Singh A, Sharma K, Dhasmana D, Dhasmana $D$, Garg N, Siril, P. Preparation, characterization and in vitro cytotoxicity of Fenofibrate and Nabumetone loaded solid lipid nanoparticles. Mater Sci Eng C 2020, 106: 110184.

11. Windbergs $M$, Strachan $C J$, Kleinebudde $P$. Investigating the principles of recrystallization from glyceride melts. AAPS PharmSciTech 2009, 10: 1224-1233.

12. Russo E, Villa C. Poloxamer 188 hydrogels for biomedical applications. Pharmaceutics 2019, 11: 671.

13. Gardouh, AR, Gad S, Ghonaim HM, Ghorab MM. Design and characterization of glyceryl monostearate solid lipid nanoparticles prepared by high shear homogenization. $J$ Pharm Res 2013, 3: 326-346.

14. Jangde $R$, Singh $D$. Compatibility studies of quercetin with pharmaceutical excipients used in the development of novel formulation. Research $\mathrm{J}$ Pharm and Tech 2014, 7: 1101-1105.

15. Wieduwilt MJ, Moasser MM. The epidermal growth factor receptor family: biology driving targeted therapeutics. Cell Mol Life Sci 2008, 65: 1566-1584.

16. Affram KO, Smith T, Ofori E, Krishnan S, Underwood $P$, Jose G, Trevino JG, Agyare E. Cytotoxic effects of gemcitabine-loaded solid lipid nanoparticles in pancreatic cancer cells. J drug del sci tech 2020, 55: 101374.

17. Pizzol CD, Filippin-Monteiro FB, Restrepo JA, Pittella $F$, Silva AH, Alves de Souza P, Machado de Campos A, Creczynski-Pasa TB. Influence of surfactant and lipid type on the physicochemical properties and biocompatibility of solid lipid nanoparticles. Int J Environ Res Public Health 2014, 11: 8581-8596.

18. Hao J, Fang X, Zhou Y, Wang J, Guo F, Li F, Peng X. Development and optimization of solid lipid nanoparticle formulation for ophthalmic delivery of chloramphenicol using a Box-Behnken design. Int J Nanomedicine 2011, 6: 683-692.

19. Oliveira MS, Mussi SV, Dawidson A Gomes DA, Yoshida MI, Frezard F. Tocopherol succinate improves encapsulation and anticancer activity of doxorubicin loaded in solid lipid nanoparticles. Colloids Surf $B$ Biointerfaces 2016, 140: 246-253.

20. Carvalho IPS, Miranda MA, Silva LB, ChrysostomoMassaro TN, Paschoal JAR, Bastos JK, Marcato PD. In vitro anticancer activity and physicochemical properties of SOLANUM LYCOCARPUM alkaloidic extract loaded in natural lipid-based nanoparticles. Colloids Interface Sci Commun 2019, 28: 5-14.

21. Shigeta $K$, Hayashida $T$, Hoshino $Y$, Shigeta $K$, Hayashida T, Hoshino Y. Expression of epidermal growth factor receptor detected by cetuximab indicates its efficacy to inhibit in vitro and in vivo proliferation of colorectal cancer cells. PLoS One 2013, 8: e66302.

22. Allotey-Babington GL, Nettey H, D'Sa, S, Gomes K, D'Souza MJ. Cancer chemotherapy: Effect of poloxamer 188 modified nanoparticles on cellular function. J drug del sci tech 2018, 47: 181-192.

23. Yan F, Zhang C, Zheng Y, Mei L, Tang L, Song C. The effect of poloxamer 188 on nanoparticle morphology, size, cancer cell uptake, and cytotoxicity. Nanomedicine 2010, 6: 170-178. 